\title{
Feeding practices in 6-24-month-old children with chronic cholestatic liver diseases: a mixed-method study
}

\author{
Xiao Chen ${ }^{1,2}$, Jianshe Wang ${ }^{1}$, Yi Lu', Xinbao Xie ${ }^{1}$, Ying Gu ${ }^{3}$, Jos M. Latour ${ }^{4}$ and Yuxia Zhang ${ }^{2^{*}}$ (D)
}

\begin{abstract}
Background: Children with chronic cholestatic liver diseases have a high risk of malnutrition. However, nutritional management in China has received little attention, and there has been limited evidence regarding improving these practices. This study aimed to evaluate the feeding status of chronic cholestatic children aged 6-24 months and to explore their parents' experiences with feeding practices.
\end{abstract}

Methods: A mixed-method study was conducted among parents of 74 children with chronic cholestatic liver diseases. The Infant and Young Child Feeding Index (ICFI) was used to collect quantitative data of feeding practices. In-depth interviews with parents were performed to generate qualitative data. Multivariate analysis was conducted to identify predictors of inappropriate feeding practices. Qualitative data were analyzed using thematic analysis.

Results: Only $16.2 \%$ of the children had appropriate feeding practices. In terms of dairy products, the rate of breastfeeding, medium-chain triglyceride formula feeding, and regular formula feeding were 25.7, 39.2 and 44.6\% respectively. The complementary feeding rate was $68.8 \%$, and the age of adding complementary foods was $6.9 \pm$ 1.7 months. Consumption of foods from animal sources was suboptimal, $66.7 \%$ of the children aged $6-8$ months and $45.5 \%$ of the children aged 9-11 months had carbohydrates as a single source of complementary foods and had no intake of meat, eggs or bean products, while in the age group 12-24 months, 52.0\% of the children had eggs less than 2 days/week, $60.0 \%$ had meat less than 2 days/week, and $60.0 \%$ had no intake of bean products. Low literacy of the primary care provider was significantly related to inappropriate feeding practices (adjusted OR 5.52; $95 \% \mathrm{Cl} 1.29,23.66)$. The result of the interviews indicated that parents generally lacked the scientific knowledge of feeding and thought that the intake of animal source foods and oils would be a burden to the liver and cause damage to the liver functions.

Conclusion: Parents generally lacked science-based feeding knowledge and the feeding practices in 6-24-monthold children diagnosed with chronic cholestatic liver diseases fell short of the recommendations in current nutritional guidelines. Appropriate interventions targeting social and cultural family circumstances should therefore be included in supporting parents in feeding practices to improve children's clinical outcomes.

Keywords: Cholestatic liver disease, Feeding practices, Medium-chain triglyceride, Complementary food, Feeding experiences

\footnotetext{
*Correspondence: zhang.yx@aliyun.com

${ }^{2}$ Department of Nursing, Zhongshan Hospital of Fudan University, No.180,

Fenglin road, Shanghai, People's Republic of China

Full list of author information is available at the end of the article
}

(C) The Author(s). 2020 Open Access This article is licensed under a Creative Commons Attribution 4.0 International License, which permits use, sharing, adaptation, distribution and reproduction in any medium or format, as long as you give appropriate credit to the original author(s) and the source, provide a link to the Creative Commons licence, and indicate if changes were made. The images or other third party material in this article are included in the article's Creative Commons licence, unless indicated otherwise in a credit line to the material. If material is not included in the article's Creative Commons licence and your intended use is not permitted by statutory regulation or exceeds the permitted use, you will need to obtain permission directly from the copyright holder. To view a copy of this licence, visit http://creativecommons.org/licenses/by/4.0/ The Creative Commons Public Domain Dedication waiver (http://creativecommons.org/publicdomain/zero/1.0/) applies to the data made available in this article, unless otherwise stated in a credit line to the data. 


\section{Background}

Severe malnutrition affects approximately $40-70 \%$ of the children with chronic cholestatic liver diseases [1-3]. The impacts of malnutrition on children's outcomes include increased risks of pre- and post liver transplantation morbidity and mortality, immune suppression, and impaired neurocognitive development [4-6]. Therefore, it is important to perform nutritional management, including nutritional assessment, intervention, and followup, to prevent negative health outcomes among children. Nutritional assessments, the cornerstone of nutritional management, can identify the impaired nutritional status in a timely manner and can clarify the existing problems in feeding practices [7-9]. It is recommended to perform routine nutritional assessments in daily clinical practices; these assessments should be comprehensive, should involve anthropometric measurements, and detailed feeding histories, and should include social and cultural factors influencing feeding practices [9].

Only a few studies focusing on the dietary intake status of children with chronic cholestatic liver diseases have been reported. Rovner et al. investigated 26 children with Alagille syndrome and found that more than $20 \%$ of these children were consuming less than twothirds of the recommended daily allowance (RDA) of calories, fat, calcium, vitamin D, and vitamin E [10]. Shiga et al. reported that the mean energy intake in children with biliary atresia was $84 \%$ of RDA [11].

Previous studies revealed that the feeding practices were suboptimal, but these studies lacked detailed descriptions and analyses of dietary intake and had small sample sizes. In addition, these studies were conducted before the feeding guidelines for children with chronic cholestasis were published; thus, their conclusions were drawn through comparison to the RDA of normal children instead of cholestatic children [11, 12]. Moreover, the reasons behind parents' feeding practices remain unclear, making it difficult to cost-effectively promote behavioral changes.

Although the morbidity of children with chronic cholestatic liver diseases is low globally [13], the number of these children in China is considerable because of the large overall population. However, nutritional management in China has received little attention, and there has been limited evidence regarding improving these practices. Investigating feeding practices according to the latest guidelines for nutrition management could provide a foundation for further tailoring care plans for nutritional support.

The first 2 years after birth represent the most important period for the growth and development of a child. Nutrition during this period not only influences children's physical development, but also profoundly affects on neurobehavioral development and healthy dietary habits [14]. For 6-24-months-old children, the nutrient requirements cannot be fully met by dairy products, and parents' feeding behaviors play a crucial role in the nutritional management. Therefore, this study aimed to evaluate the feeding status of chronic cholestatic children aged 6-24 months and to explore their parents' experiences with feeding practices.

\section{Methods}

The study adopted a mixed-method design. The quantitative method used the Infant and Young Child Feeding Index survey to evaluate feeding practices. The qualitative method used semistructured interviews with parents to explore their feeding experiences and analyze barriers to appropriate feeding practices. The study is reported using the reporting guideline of 'the quality of mixed methods studies in health services research' [15] obtained from the EQUATOR-network website.

\section{Quantitative method Participants}

Parents of children with chronic cholestatic liver diseases were consecutively recruited from January 2016 until March 2017 at the Children's Hospital of Fudan University in Shanghai, China. Inclusion criteria were parents who had 6-24-month-old children with chronic cholestatic liver diseases, defined as a diagnosis established by gene sequencing or presence of at least 6 months of typical clinical and biochemical derangements [16]. Parents were excluded if the child was a premature infant, had other serious diseases seriously influencing feeding, or could not receive normal feeding due to progressive deterioration of conditions, such as acute liver failure.

\section{Sample size}

A single population proportion formula was used to determine the sample size based on the following assumptions. The proportion of appropriate feeding practices was $80 \%$ [10], with a $95 \%$ CI, $10 \%$ margin of error (d), and $10 \%$ nonresponse rate, resulting in a sample size of 74 .

\section{Data collection}

Children with chronic cholestatic liver diseases routinely visited the outpatient clinic for regular follow-up and adjustment of medical treatment. After visiting the outpatient service, parents of eligible children were invited to participate in the study.

Demographic characteristics, including sex, date of birth, gestational age, birth weight, literacy of parents, and monthly household income, were collected by asking the parents. Laboratory data were obtained from the medical records, including alanine aminotransferase, aspartate aminotransferase, total bilirubin, direct bilirubin, and gamma-glutamyl transpeptidase level. 
Feeding practices were measured using the Infant and Young Child Feeding Index (ICFI), which was designed by the 'Chinese Center for Disease Control and Prevention' according to the WHO recommendations of child feeding practices [17]. The ICFI has been widely used to assess the dietary intake of children aged 6-24 months and has been suggested to be efficient in assessing parents' feeding practice in China. Numerous studies have shown that the ICFI is strongly associated with the status of children's growth and development $[18,19]$. The ICFI is a comprehensive index and includes seven variables and thirteen items: breastfeeding, bottle feeding, dietary diversity for the past $24 \mathrm{~h}$, frequency of food (grains, vegetables, fruits, eggs, flesh foods, bean products, and dairy products) for the past 7 days, first formula milk feeding age, first complementary feeding age, and frequency of complementary feeding for the past 24 h. Breastfeeding and bottle feeding were assessed by a 2point scale (yes/no), while the other items were assessed on either a 2-point or 3-point Likert scale (Electronic Supplemental Material 1). The range of the total score was $0-23$, and higher scores indicated better feeding practices. Appropriate feeding practice was determined when the score was greater than $60 \%$ of the possible score, and inappropriate feeding practice was defined as ICFI $<14$. In addition, given the unique nutrient requirements of children with chronic cholestatic liver diseases $[8,20]$, two ad-hoc questions were added to the survey to identify the intake of dairy products and medium chain triglycerides.

\section{Statistical analysis}

Descriptive data were expressed as either means and SDs, medians and interquartile ranges for continuous variables or frequencies for categorical variables. The Shapiro-Wilk test showed that the levels of total bilirubin, direct bilirubin, glutamyl transpeptidase, alanine aminotransferase, and aspartate aminotransferase had nonnormal distribution. These data were therefore expressed as the median and interquartile range (IQR).

When we analyzed the determinants of feeding practice, bivariate analysis was first conducted between the feeding index and each variable, including sex of child, age of child, birth order of child, family monthly income per capita, literacy of primary care provider, presence of cholestasis (direct bilirubin), and area of residence. Primary care providers were defined as those who took the main responsibility for disease management, feeding and daily activities. The variables marginally associated $(p<$ 0.10 ) with the feeding index in the bivariate analysis were selected for multivariate analyses. Then, multivariate analysis was conducted for the feeding index with potential risk factors. In the final model, only variables significantly associated $(p<0.05)$ with outcome variables were retained, and the adjusted odds ratio (AOR) and 95\% confidence interval (CI) were reported. Children with missing data were excluded from in the model.

All statistical analyses were performed using IBMSPSS, version 22 (IBM Corp, Armonk, NY, USA). The significance level was set at $p<0.05$.

\section{Qualitative design \\ Sampling}

After the survey of feeding practices, to determine the motives behind inappropriate feeding practices and promote behavioral changes, we purposefully approached participants with an ICFI score $<14$. We continued data collection until thematic saturation was observed, which meant that there were no new codes or themes occurring during the ongoing analysis [21]. In total, ten mothers and one father participated in the interviews.

\section{Interviews}

Interviews with parents were conducted in a quiet meeting room in the hospital. A semistructured interview guide was developed. Example questions were as follows: 'How did you feed your child?', 'What were the sources of your feeding knowledge?', and 'Can you explain any confusion or uncertainty about how to feed your child?'. The duration of the face-to-face interviews was $30-60$ min. All interviews were audio-recorded and transcribed verbatim within $24 \mathrm{~h}$ after the interview.

\section{Data analysis}

Thematic analysis was carried out by structuring data, initial coding, categorizing experiences and perceptions, and identifying themes [22].

The first author (XC) read all transcripts, identified and sorted meaningful units that elucidated the study question and categorized the units into preliminary topics. Then, the interview transcripts were individually coded by two researchers (XC and YZ) and checked for similarities. Discrepancies were solved by discussion between the two researchers. Subsequently, we organized and categorized the codes into subthemes/themes, which were discussed with two other researchers (YG and JML).

\section{Ethical considerations}

The study was approved by the Research Ethics Committee of the Children's Hospital of Fudan University (approval number 2014-143) and was performed in accordance with the ethical standards of the 1964 Declaration of Helsinki and its later amendments. Informed consent was obtained after providing information sheet and verbally explaining the study aims and procedures. Participation was voluntary and each parent signed a written consent form. 


\section{Results}

In total, 74 children were included in the study. The demographic and clinical characteristics of the children are presented in Table 1 . The etiologies of cholestasis were Alagille syndrome $(n=27 ; 36.5 \%)$, biliary atresia $(n=16 ; 21.6 \%)$, neonatal intrahepatic cholestasis caused by citrin deficiency $(n=8 ; 10.8 \%)$, progressive familial intrahepatic cholestasis $(n=13 ; 17.6 \%)$, congenital bile acid synthesis defects $(n=4 ; 5.4 \%)$, Dubin-Johnson syndrome $(n=3 ; 5.4 \%)$, cystic fibrosis $(n=1 ; 2.7 \%)$, and idiopathic cholestatic liver disease $(n=2 ; 2.7 \%)$.

\section{Feeding practice}

Only $16.2 \%(12 / 74)$ of the children had appropriate feeding practices, and the median ICFI score was 6 , with a range of $2-18$.

\section{Diary product intake}

The intake rates of dairy products were breastfeeding $25.7 \%$ (19/74), medium-chain triglyceride (MCT) formula feeding $39.2 \%(29 / 74)$, and regular formula feeding $44.6 \%(33 / 74)$.

\section{Complementary feeding practices}

The rate of complementary feeding was 68.8\% (51/74), and the mean age of adding complementary food was 6.9 (SD 1.7) months. For children consuming

Table 1 Baseline clinical characteristics of the study participants $(n=74)$

\begin{tabular}{|c|c|}
\hline Characteristics & Value \\
\hline Male gender of children, $\mathrm{n}(\%)$ & $39(52.7 \%)$ \\
\hline \multicolumn{2}{|l|}{ Age of children, $n(\%)$} \\
\hline $6-8$ months & $31(41.9 \%)$ \\
\hline 9-11 months & $16(21.6 \%)$ \\
\hline 12-24 months & $27(36.5 \%)$ \\
\hline \multicolumn{2}{|l|}{ Household monthly income per capita, $n(\%)$} \\
\hline$\leq 5000 \mathrm{RMB}$ & $50(67.6 \%)$ \\
\hline$>5000 \mathrm{RMB}$ & $24(32.4 \%)$ \\
\hline \multicolumn{2}{|l|}{ Literacy of primary care provider, $\mathrm{n}(\%)$} \\
\hline High school or below & $44(59.5 \%)$ \\
\hline College degree or above & $30(40.5 \%)$ \\
\hline Presence of cholestasis, $n(\%)$ & $55(74.3 \%)$ \\
\hline Total bilirubin $(\mu \mathrm{mol} / \mathrm{L})$, median (IQR) & $65.1(19.0-183.8)$ \\
\hline Direct bilirubin ( $\mu \mathrm{mol} / \mathrm{L})$, median (IQR) & $48.9(12.3-112.7)$ \\
\hline GGT (IU/L), median (IQR) & $87.0(34.0-315.0)$ \\
\hline ALT (IU/L), median (IQR) & $110.0(67.8-211.5)$ \\
\hline AST (IU/L), median (IQR) & $137.0(79.5-248.0)$ \\
\hline 25-hydroxy-vitamin D (ng/ml), median (IQR) & $12.8(8.6-24.6)$ \\
\hline
\end{tabular}

Abbreviations: GGT Glutamyl transpeptidase, ALT Alanine aminotransferase, AST Aspartate aminotransferase complementary foods, their dietary diversity involved single food groups with low energy density. A total of $66.7 \%(10 / 15)$ of children aged 6-8 months and $45.5 \%$ (5/11) of children aged 9-11 months had carbohydrates as a single source of complementary foods and had no intake of animal meat (meat, fish, poultry and liver/ organ meats), eggs or bean products, while in the age group 12-24 months, $52.0 \%(13 / 25)$ of children had eggs less than 2 days/week, $60.0 \%(15 / 25)$ had meat less than 2 days/week, and $60.0 \%(15 / 25)$ had no intake of bean products (Table 2 ).

\section{Medium-chain triglyceride intake}

The rate of MCT intake was 40.5\% (30/74), and among 30 children, 29 received MCTs entirely from specialized formula, while only one child was fed with MCT via the complementary foods.

\section{Determinants of inappropriate feeding practices}

The bivariate analysis showed that the rate of inappropriate feeding practices was potentially associated with the age of the child and the literacy of the primary care provider. After controlling for potential confounding factors, the literacy of the primary care provider was significantly related to inappropriate feeding practices (Table 3). Parents without a college degree had a higher risk of inappropriate feeding behaviors than collegeeducated parents (adjusted OR 5.52; 95\% CI 1.29, 23.66).

\section{Feeding experiences of parents}

Ten mothers and one father of children participated in the interviews (Table 4). Three main themes emerged from the thematic analysis: (1) lack of knowledge of feeding; (2) misunderstanding of the feeding process; and (3) lack of importance of complementary foods. An overview of the themes, subthemes and related quotations of the parents is provided in Table 5 .

\section{Lack of knowledge of feeding}

All parents expressed their confusion about feeding their children, especially concerning the varieties, quantity and the introduction age of complementary food. There seemed to be a lack of information provided by the healthcare system, and other information sources might be difficult to find on Chinese websites. "I am completely blank and tried to look for information on the internet, but there was little relevant information. I am really at a loss and don't know how to feed him, and am afraid wrong food would damage his health" (participant A). The lack of information was confirmed by another mother, who said, "I felt guilty every time seeing my child was so thin, but I had no idea how to feed him to help him get fat" (participant E). The consequence of the 
Table 2 Infant and Young Child feeding index (ICFI) components by age group

\begin{tabular}{|c|c|c|c|c|c|c|}
\hline \multirow[t]{3}{*}{ Components } & \multicolumn{6}{|l|}{ Age group } \\
\hline & \multicolumn{2}{|c|}{ 6-8 months $(n=31)$} & \multicolumn{2}{|c|}{ 9-11 months $(n=16)$} & \multicolumn{2}{|c|}{$12-24$ months $(n=27)$} \\
\hline & classification & n (\%) & classification & n (\%) & classification & n (\%) \\
\hline \multirow[t]{3}{*}{ Dietary diversity } & 0 group & $16(51.6 \%)$ & $0-1$ group & $7(43.8 \%)$ & $0-2$ groups & $8(29.6 \%)$ \\
\hline & $1-2$ groups & $12(38.7 \%)$ & $2-3$ groups & $4(25.0 \%)$ & $3-4$ groups & $12(44.5 \%)$ \\
\hline & $\geq 3$ groups & $3(9.7 \%)$ & $\geq 4$ groups & $5(31.2 \%)$ & $\geq 5$ groups & $7(25.9 \%)$ \\
\hline \multirow[t]{3}{*}{ Meal frequency } & 0 meal & $16(51.6 \%)$ & 0-1 meal & $7(43.8 \%)$ & $0-2$ meals & $11(40.7 \%)$ \\
\hline & 1 meal & $8(25.8 \%)$ & 2 meals & $7(43.8 \%)$ & 3 meals & $16(59.3 \%)$ \\
\hline & $\geq 2$ meals & $7(22.6 \%)$ & $\geq 3$ meals & $2(12.4 \%)$ & $\geq 4$ meals & $0(0.0 \%)$ \\
\hline \multirow[t]{3}{*}{ Egg frequency } & 0 day & $27(87.0 \%)$ & 0 day & $11(68.8 \%)$ & $0-2$ days & $15(55.6 \%)$ \\
\hline & $1-2$ days & $2(6.5 \%)$ & $1-3$ days & $3(18.8 \%)$ & $3-4$ days & $6(22.2 \%)$ \\
\hline & $\geq 3$ days & $2(6.5 \%)$ & $\geq 4$ days & $2(12.5 \%)$ & $\geq 5$ days & $6(22.2 \%)$ \\
\hline \multirow[t]{3}{*}{ Meat frequency } & 0 day & $29(93.6 \%)$ & 0 day & $11(68.8 \%)$ & $0-2$ days & $17(63.0 \%)$ \\
\hline & $1-2$ days & $1(3.2 \%)$ & $1-3$ days & $4(25.0 \%)$ & $3-4$ days & $5(18.5 \%)$ \\
\hline & $\geq 3$ days & $1(3.2 \%)$ & $\geq 4$ days & $1(6.2 \%)$ & $\geq 5$ days & $5(18.5 \%)$ \\
\hline \multirow[t]{3}{*}{ Fruit frequency } & 0-1 day & $26(83.9 \%)$ & $0-2$ days & $9(56.3 \%)$ & 0-3 days & $12(44.4 \%)$ \\
\hline & 2-3 days & 4 12.9\%) & $3-4$ days & $2(12.5 \%)$ & $4-5$ days & $4(14.8 \%)$ \\
\hline & $\geq 4$ days & $1(3.2 \%)$ & $\geq 5$ days & $5(31.2 \%)$ & $\geq 6$ days & $11(40.8 \%)$ \\
\hline \multirow[t]{2}{*}{ Grain frequency } & $0-4$ days & $20(64.5 \%)$ & 0-4 days & $4(25.0 \%)$ & $0-5$ days & $1(3.7 \%)$ \\
\hline & $\geq 5$ days & $11(35.5 \%)$ & $\geq 5$ days & $12(75.0 \%)$ & $\geq 6$ days & $26(96.3 \%)$ \\
\hline
\end{tabular}

absence of support to parents with regard to feeding practices is identified in the second theme.

\section{Misunderstanding of the feeding process}

All but one parent thought that their children should be treated as abnormal and their diets should be as mild as possible. This theme led to two subthemes. The first subtheme was 'Animal source food and oil will cause damage to the liver', where parents expressed their ideas and anxiety about using certain foods. One parent said, "I thought food such as eggs, meats, and oil should be limited from my child's diet because these foods could cause damage to the liver. Other mothers in the communication group shared the same idea with me" (participant E). The parents' ideas about using certain foods sometimes came from family and friends; these ideas were taken seriously by the parents and included statements such as, "People around me said the diet of children with poor liver function should be as bland as possible. Therefore, my child just had porridge, rice, and noodles besides milk" (participant G). This could lead to misconceptions such as those expressed by one parent, "I felt food like meat, eggs, and oil could burden the liver and aggravate the liver function" (participant J). The second subtheme was 'the need to control the intake due to the poor digestive function'. For example, one parent expressed, "My mother-in-law always tried to feed baby the egg yolk, but I worried that my baby couldn't ingest it and refused to feed these foods" (participant F).

\section{Lack of importance of complementary food}

Several parents thought that milk had higher nutritional value than complementary food and gave no importance to complementary food: "I had never tried to introduce

Table 3 Determinants of inappropriate feeding practices

\begin{tabular}{lll}
\hline Variables & Rate of inappropriate feeding practice & $\begin{array}{l}\text { Adjusted OR } \\
\text { (95\% Cl) }\end{array}$ \\
\hline $\begin{array}{l}\text { Year of child } \\
<12 \text { months }\end{array}$ & \\
$\quad 87.2 \%$ & $1.24(0.32-4.75)$ \\
$\quad \geq 12$ months & $77.8 \%$ & 1.00 \\
Primary care provider's literacy & & \\
$\quad$ High school or below & $93.2 \%$ & $5.52(1.29-23.66)$ \\
College school or above & $70.0 \%$ & 1.00 \\
\hline
\end{tabular}


Table 4 Characteristics of parent interviews

\begin{tabular}{lllll}
\hline Number & $\begin{array}{l}\text { Age of child } \\
\text { (months) }\end{array}$ & Gender of child & Literacy of interviewee & $\begin{array}{l}\text { Monthly household income } \\
\text { (RMB per capita) }\end{array}$ \\
\hline A & 8 & male & junior college & $>5000$ \\
B & 12 & female & primary school or below & $1000-2999$ \\
C & 8.5 & male & junior high school & $1000-2999$ \\
D & 14 & female & senior high school & $3000-5000$ \\
E & 10 & male & junior high school & $3000-5000$ \\
F & 9 & male & undergraduate & $1000-2999$ \\
G & 7.5 & female & junior college & $3000-5000$ \\
H & 8 & male & undergraduate & $>5000$ \\
I & 8 & male & primary school or below & $3000-5000$ \\
J & 19 & female & postgraduate & $>5000$ \\
K & 13 & male & senior high school & $>5000$ \\
\hline
\end{tabular}

Abbreviations: $R M B$ Renminbi

complementary food because I thought milk contained higher nutritional value and worried my baby would be even thinner after decreasing the volume of milk" (participant C) and "I felt milk had more nutrients than complementary food and therefore fed her milk as much as possible" (participant G).

\section{Discussion}

The aim of our study was to evaluate the feeding status of children with chronic cholestatic liver diseases and to identify their parents' experiences of feeding practices. Overall, the feeding practices of children appeared to fall short of the recommendations, specifically those related to medium-chain triglyceride oil supplementation and complementary feeding. Lower literacy of the primary care provider was related to inappropriate feeding practices. The interviews with parents indicated that parents had limited feeding knowledge that influenced their daily feeding practices.

Children with chronic liver disease have a greater energy requirements than healthy children [23, 24], and a decrease in the oral intake could predispose these children to a worse nutritional status [25]. Children older than 6 months need to gain some energy and nutrients from complementary feeding, and parents' nutritional knowledge and feeding practices have significant impact on children's growth and development. According to the current guidelines for nutritional management, feeding practices should be maintained as close to those of healthy age-matched children as possible [7-9]. However, in our study, most children were not introduced to complementary foods in a reasonable manner. The consumption of food from animal sources was suboptimal, and carbohydrates were the main source of energy in the complementary foods, with a lack of adequate amounts of meat and eggs. Inappropriate feeding behaviors resulted in a low energy density of the meals that did not contribute to the child's growth and development.

These feeding practices did not follow the recommendations of the current guidelines, which recommend that the total energy intake should be 100 to $150 \%$ of that for an ideal weight, guided by the severity of failure to

Table 5 Themes, sub-themes and parent quotations

\begin{tabular}{|c|c|c|}
\hline Themes & Sub-themes & Parent quotations \\
\hline $\begin{array}{l}\text { Lack of knowledge } \\
\text { of feeding }\end{array}$ & & $\begin{array}{l}\text { "I tried to search information on the internet, but I still didn't know what should I } \\
\text { feed him, to avoid making mistakes, I only fed my baby with milk." (participant C) } \\
\text { "Children with jaundice must be different from normal children, I was not sure } \\
\text { which kind of food could benefit her and which kind of food would cause damage } \\
\text { to her." (participant G) }\end{array}$ \\
\hline \multirow[t]{2}{*}{$\begin{array}{l}\text { Misunderstanding of } \\
\text { the feeding process }\end{array}$} & $\begin{array}{l}\text { Animal source food and oil will } \\
\text { cause damage to the liver }\end{array}$ & $\begin{array}{l}\text { "My baby had poor liver function, I felt flesh foods and eggs would aggravate his } \\
\text { condition therefore I did not dare to feed him with these foods." (participant B) } \\
\text { "I thought flesh foods should be limited from my baby's diets, because these foods } \\
\text { did no good to the liver." (participant K) }\end{array}$ \\
\hline & $\begin{array}{l}\text { The need to control the intake due } \\
\text { to the poor digestive function }\end{array}$ & $\begin{array}{l}\text { "I felt these children with jaundice had poor ability to digest, so they shouldn't be } \\
\text { fed too much, especially eggs and flesh foods." (participant H) }\end{array}$ \\
\hline $\begin{array}{l}\text { Lack of importance of } \\
\text { complementary foods }\end{array}$ & & $\begin{array}{l}\text { "Milks seemed to contain more nutrients, so I did not feed my child complementary } \\
\text { food until he aged } 11 \text { months." (participant D) }\end{array}$ \\
\hline
\end{tabular}


thrive, and that $3-4 \mathrm{~g} / \mathrm{kg} / \mathrm{d}$ of protein is necessary for children without a risk of hepatic encephalopathy [7-9]. However, these results were not in line with those of a study performed in Japan, which showed that $20 \%$ of children with Alagille syndrome had low dietary intake [10]. The variation among these studies could be due to sociocultural differences and different definitions of inadequate feeding. The Japanese study was conducted before the publication of feeding guidelines for children with chronic cholestasis, and inadequate intake was defined as consuming $<2 / 3$ of the RDA. In our study, we defined inadequate intake as ICFI $<14$ according to current guidelines.

Another important finding of our study was that the majority of parents were unaware of children's specific nutritional requirements for MCTs. MCTs are absorbed directly through the portal venous system without the emulsification with bile [26], and supplementing MCTs can prominently decrease steatorrhea and improve growth in children with cholestasis $[27,28]$. Thus, the $30-50 \%$ of total lipids are recommended to be given as MCTs in cholestatic patients, and in older children, MCT oil can be added to meals to increase energy density [8]. However, in our study, only a few children had enough intake of MCTs, and the source of MCTs was almost exclusively from specialized MCT formula. Only one mother reported that she added MCT oil in the complementary food, but she gave a small amount because of unpalatability. Compared with MCT oil, coconut oil may be a preferable choice, because $60-70 \%$ of the components in coconut oil are MCTs [29] and coconut oil does not make the food unpalatable $[8,20]$.

The deficiency of fat-soluble vitamins (A, D, E, and K) among children with chronic cholestasis are prevalent, which are primarily caused by fat malabsorption. Increasing oral fat intake may increase the total quantity of fat absorbed and improve growth and development despite causing steatorrhea [8]. However, in this study, the total fat intake was insufficient due to the inadequate intake of animal foods and vegetable oil. Future studies should further determine associations between the dietary intake and level of serum fat-soluble vitamins.

A logistic regression model was used to further evaluate the predictors of inappropriate feeding practices. The results indicated that after adjustment for covariates, only the literacy of the primary care provider was an independent predictor of inappropriate feeding practices. However, household monthly per capita income, a predictor of feeding behaviors among normal children [30, 31], was not significantly associated with feeding practices in children with chronic cholestatic liver diseases in this study. This finding was consistent with clinical observations; due to the low morbidity of the disease and the absence of reliable information sources, parents generally lacked science-based feeding knowledge. It was not the economic factor but incorrect ideas that contributed to inappropriate feeding practices.

Appropriate feeding of infants and young children feeding is required for optimal childhood nutrition, health and development [32]. To further explore the barriers of parents' appropriate feeding behaviors and to provide practical information for clinical nutritional interventions to promote behavioral changes, we conducted interviews with parents. The findings indicated that a lack of knowledge of feeding, misunderstanding of the feeding process, and lack of importance of complementary foods emerged as important barriers to appropriate feeding practices. The most common misunderstanding to emerge was that animal source foods and oil will cause damage to the liver. One study in the Democratic Republic of the Congo also showed that the main barriers to optimal infant and young children feeding practices included a lack of knowledge and the presence of misconceptions among parents [33]. Another study on feeding practices in the Bolivian Andes found that parents' lack of understanding of the importance of complementary feeding contributed to inappropriate feeding behaviors [34]. Moreover, due to the absence of effective interventions from clinical professionals, these wrong concepts and behaviors of parents spread among the community and became cumulatively reinforced, leading to a widespread misunderstanding about feeding practices.

Our study warrants some limitations. Firstly, this was a single-center study and our findings therefore may not be generalized. However, Children's Hospital of Fudan University has been authorized by the government to be the first center of pediatric liver diseases in China. Children from all over the nation are admitted and treated in this hospital, thus for the Chinese region, our sample can be considered representative to some extent. Secondly, we did not assess children's nutrients intake through dietary records. However, ICFI is a comprehensive index and has been widely used to assess dietary intake of children aged 6-24 months in China. Therefore our study provided important information for clinical practices.

The clinical implications of our study are related to healthcare professionals. Without access of parents to reliable sources of feeding knowledge, healthcare professionals play an important role in influencing parents to adopt positive practices. It is critical to establish a multidisciplinary care team to implement nutritional management targeting social and cultural family circumstances. These management strategies increase parents' access to scientific knowledge about nutrition and the special nutritional needs of children so that parents can optimize their feeding behaviors and improve the nutritional 
status of children. Notably, considering that parents had serious misunderstanding about how to feed children with chronic cholestasis, appropriate interventions, such as providing various education materials for parents, should therefore be included in clinical disease management to enhance compliance with the nutritional plan.

\section{Conclusions}

Nutrition received during the first 2 years not only influences children's physical development, but also profoundly affects neurobehavior development and healthy dietary habits. As healthcare providers, we do not know enough about how children with chronic cholestatic liver diseases are fed, what hinders appropriate feeding practices, and what makes further interventions work. This study adds contextual understanding to the feeding practices in children with chronic liver diseases by adopting a mixed-method study. The results showed that feeding practices in these children are characterized by a lack of dietary diversity and an inadequate intake of MCTs, and feeding practices may be influenced by parents' lack of feeding knowledge, their misunderstanding of the feeding process, and their lack of importance of complementary food. We hope that the findings in this study will provide practical information for clinical nutritional interventions to make impactful, cost-effective, targeted and sustainable interventions, so as to promote parents' behavioral changes among parents, improve children's growth and prevent stunted growth.

\section{Supplementary information}

Supplementary information accompanies this paper at https://doi.org/10. 1186/s12887-020-02290-8.

Additional file 1. The scoring system of the infant and child feeding index for children aged 6-24 months.

\section{Abbreviations}

RMB: Renminbi; GGT: Glutamyl transpeptidase; ALT: Alanine aminotransferase; AST: Aspartate aminotransferase

\section{Acknowledgments}

The authors thank all parents and children for participating in this study and providing their valuable experiences.

\section{Authors' contributions}

$X C$, JW, and $Y Z$ contributed to the development of the study protocol. XC, JW, YL and XX contributed to recruitment and data collection. Data was analyzed by $X C, Y G, J M L$ and $Y Z$. $X C, J M L$ and $Y Z$ drafted the first manuscript and JW, YL, $X X$ and $Y G$ provided comments on revisions. All authors have approved the final manuscript and ensured that questions related to the accuracy or integrity of any part of the work are appropriately investigated and resolved.

\section{Funding}

This study was funded by the Shanghai Municipal Commission of Health and Family Planning Key Developing Discipline (number 2015ZB0302). For the remaining authors, none is declared. The funder had no role in the design of the study, the collection or analysis of data, or the decision to publish.

\section{Availability of data and materials}

The datasets used and analysed during the current study are available from the corresponding author on reasonable request.

\section{Ethics approval and consent to participate}

The study was approved by the Research Ethics Committee of the Children's Hospital of Fudan University (approval number 2014-143) and was performed in accordance with the ethical standards of the 1964 Declaration of Helsinki and its later amendments. Informed consent was obtained after providing information sheet and verbally explaining the study aims and procedures. Participation was voluntary and each parent signed a written consent form.

Consent for publication

Not applicable.

\section{Competing interests}

The authors declare that they have no competing interests.

\section{Author details}

${ }^{1}$ Department of Liver Disease, Children's Hospital of Fudan University, Shanghai, People's Republic of China. ${ }^{2}$ Department of Nursing, Zhongshan Hospital of Fudan University, No.180, Fenglin road, Shanghai, People's Republic of China. ${ }^{3}$ Department of Nursing, Children's Hospital of Fudan University, Shanghai, People's Republic of China. ${ }^{4}$ School of Nursing and Midwifery, Faculty of Health and Human Sciences, University of Plymouth, Plymouth, UK

Received: 18 January 2020 Accepted: 12 August 2020

Published online: 24 August 2020

\section{References}

1. Yuksekkaya HA, Cakir M, Tumgor G, Baran M, Arikan C, Yagci RV, Aydogdu S. Nutritional stastus of infants with neonatal cholestasis. Dig Dis Sci. 2008; 53(3):803-8. https://doi.org/10.1007/s10620-007-9917-y.

2. da Silva FV, Ferri PM, Nascentes Queiroz TC, de Souza Haueisen Barbosa P, Cassiano de Oliveira MC, de Melo Pereira LJ, Silva AC SE, Penna FJ, Druve Tavares Fagundes E, Ferreira AR. Nutritional evaluation of children with chronic cholestatic disease. J Pediatr (Rio J). 2016;92(2):197-205. https://doi. org/10.1016/j.jped.2015.07.006.

3. Saron ML, Godoy HT, Hessel G. Nutritional status of patients with biliary atresia and autoimmune hepatitis related to serum levels of vitamins A, D and E. Arq Gastroenterol. 2009;46(1):62-8. https://doi.org/10.1590/s000428032009000100016.

4. Mansi Y, Ghaffar SA, Sayed S, El-Karaksy H. The effect of nutritional status on outcome of hospitalization in Paediatric liver disease patients. J Clin Diagn Res. 2016;10(12):SC01-5. https://doi.org/10.7860/JCDR/2016/21606.8956.

5. O'Keefe SJ, El-Zayadi AR, Carraher TE, Davis M, Williams R. Malnutrition and immuno-incompetence in patients with liver disease. Lancet. 1980;2(1):6157. https://doi.org/10.1016/s0140-6736(80)90284-6.

6. Caudle SE, Katzenstein JM, Karpen SJ, MCLin VA. Language and motor skills are impaired in infants with biliary atresia before transplantation. J Pediatr. 2010;156(6):936-40. https://doi.org/10.1016/j.jpeds.2009.12.014.

7. Huynh DK, Selvanderan SP, Harley HA, Holloway RH, Nguyen NQ. Nutritional care in hospitalized patients with chronic liver disease. World J Gastroenterol. 2015;21(45):12835-42. https://doi.org/10.3748/wjg.v21.i45.12835.

8. Baker A, Stevenson R, Dhawan A, Goncalves I, Socha P, Sokal E. Guidelines for nutritional care for infants with cholestatic liver disease before liver transplantation. Pediatr Transplant. 2007;11(8):825-34. https://doi.org/10. 1111/j.1399-3046.2007.00792.x.

9. Nightingale $\mathrm{S}, \mathrm{Ng}$ VL. Optimizing nutritional management in children with chronic liver disease. Pediatr Clin N Am. 2009;56(5):1161-83. https://doi.org/ 10.1016/j.pcl.2009.06.005.

10. Rovner AJ, Schall Jl, Jawad AF, Piccoli DA, Stallings VA, Mulberg AE, Zemel BS. Rethinking growth failure in Alagille syndrome: the role of dietary intake and Steatorrhea. J Pediatr Gastroenterol Nutr. 2002;35(4):495-502. https://doi.org/10.1097/00005176-200210000-00007.

11. Shiga C, Ohi R, Chiba T, Nio M, Endo N, Mito S, Hino M. Assessment of nutritional status of postoperative patients with biliary atresia. Tohoku J Exp Med. 1997;181(1):217-23. https://doi.org/10.1620/tjem.181.217. 
12. Cardoso A, Porta G, Vieira M, Carrazza FR. Nutritional evaluation of children with cholestatic diseases. J Pediatr (Rio J). 1997;73(1):43-50. https://doi.org/ 10.2223/jped.502.

13. Fawaz R, Baumann U, Ekong U, Fischler B, Hadzic N, Mack CL, Molleston JP, Neimark E, Ng VL, Karpen SJ. Guideline for the evaluation of Cholestatic jaundice in infants: joint recommendations of the north American Society for Pediatric Gastroenterology, Hepatology, and nutrition (NASPGHAN) and the European Society for Pediatric Gastroenterology, Hepatology, and nutrition (ESPGHAN). J Pediatr Gastroenterol Nutr. 2016;64(1):154-68. https:// doi.org/10.1097/MPG.0000000000001334.

14. Black RE, Allen LH, Bhutta ZA, Caulfield LE, de Onis M, Ezzati M, Mathers C, Rivera J. Maternal and child undernutrition: global and regional exposures and health consequences. Lancet. 2008;371(9608):243-60. https://doi.org/10. 1016/S0140-6736(07)61690-0.

15. O'Cathain A, Murphy E, Nicholl J. The quality of mixed methods studies in health services research. J Health Serv Res Policy. 2008;13(2):92-9. https:// doi.org/10.1258/jhsrp.2007.007074.

16. Perrin EC, Newacheck P, Pless IB, Drotar D, Gortmaker SL, Leventhal J, Perrin JM, Stein RE, Walker DK, Weitzman M. Issues involved in the definition and classification of chronic health conditions. Pediatrics. 1993;91(4):787-93.

17. Yan L, Zeng G, Sun Y. Methodology of infant and young child feeding index for children aged 6-23months in China. Wei Sheng Yan Jiu. 2012; 41(2):209-14.

18. Zhang YG, Ran YC, Li W, Ye YX, Huang ML. Investigation of current situation of complementary feeding, growth and development of infants. Chinese J Child Health Care. 2012;2(20):163-6.

19. Li CY, Huang L, Ma XC. Analysis of complementary feeding index for 4-12 months infants in Beijing. Chinese J Children Health Care. 2014;22(2):125-7.

20. Smart KM, Alex G, Hardikar W. Feeding the child with liver disease: a review and practical clinical guide. J Gastroenterol Hepatol. 2011;26(5):810-5. https://doi.org/10.1111/j.1440-1746.2011.06687.x.

21. Saunders B, Sim J, Kingstone T, Baker S, Waterfield J, Bartlam B, Burroughs H, Jinks C. Saturation in qualitative research: exploring its conceptualization and operationalization. Qual Quant. 2018;52(4):1893-907. https://doi.org/10. 1007/s11135-017-0574-8.

22. Braun V, Clarke V. Using thematic analysis in psychology. Qual Res Psychol. 2006;3(2):77-101.

23. Greer R, Lehnert M, Lewindon P, Cleghorn GJ, Shepherd RW. Body composition and components of energy expenditure in children with endstage liver disease. J Pediatr Gastroenterol Nutr. 2003;36(3):358-63. https:// doi.org/10.1097/00005176-200303000-00010.

24. Carpenter A, Ng VL, Chapman K, Ling SC, Mouzaki M. Predictive equations are inaccurate in the estimation of the resting energy expenditure of children with end-stage liver disease. J Parenter Enter Nutr. 2017;41(3):50711. https://doi.org/10.1177/0148607115597666.

25. Roggero P, Cataliotti E, Ulla L, Stuflesser S, Nebbia G, Bracaloni D, Lucianetti A, Gridelli B. Factors influencing malnutrition in children waiting for liver transplants. Am J Clin Nutr. 1997;65(6):1852-7. https://doi.org/10.1093/ajcn/ 65.6.1852.

26. Fernandes J, Van De Kamer JH, Weijers HA. Differences in absorption of the various fatty acids studied in children with steatorrhea. J Clin Invest. 1962; 41(3):488-94. https://doi.org/10.1172/JCl104502.

27. Cohen Ml, Gartner LM. The use of medium-chain triglycerides in the management of biliary atresia. J Pediatr. 1971;79(3):379-84. https://doi.org/ 10.1016/s0022-3476(71)80144-0

28. Macias-Rosales R, Larrosa-Haro A, Ortiz-Gabriel G, Trujillo-Hernández B. Effectiveness of enteral versus Oral nutrition with a medium-chain triglyceride formula to prevent malnutrition and growth impairment in infants with biliary atresia. J Pediatr Gastroenterol Nutr. 2016;62(1):101-9. https://doi.org/10.1097/MPG.0000000000000909.

29. Liang SH, Wei XZ, Zhang M, Sun C. Preparation of structured lipid enriched with medium chain triacylglycerol by chemical catalyzed Acidolysis of coconut oil: optimized by response surface methodology. J Oleo Sci. 2019; 68(12):1175-85. https://doi.org/10.5650/jos.ess19187.

30. Duan YF, Yang ZY, Lai JQ, Yu DM, Chang SY, Pang XH, Jiang S, Zhang HM. Exclusive breastfeeding rate and complementary feeding indicators in China: a National Representative Survey in 2013. Nutrients. 2018;10(2):24957. https://doi.org/10.3390/nu10020249.

31. Agho KE, Burns P, Page A, Dibley MJ. Determinants of inadequate complementary feeding practices among children aged 6-23 months in
Ghana. Public Health Nutr. 2015;18(4):669-78. https://doi.org/10.1017/ S1368980014000834.

32. Bhutta ZA, Das JK, Rizvi A, Gaffey MF, Walker N, Horton S, Webb P, Lartey A, Black RE. Evidence-based interventions for improvement of maternal and child nutrition: what can be done and at what cost? Lancet. 2013;382:45277. https://doi.org/10.1016/S0140-6736(13)60996-4.

33. Burns J, Emerson JA, Amundson K, Doocy S, Caulfield LE, Klemm RD. A qualitative analysis of barriers and facilitators to optimal breastfeeding and complementary feeding practices in south Kivu, Democratic Republic of Congo. Food Nutr Bull. 2016;37:119-31. https://doi.org/10.1177/ 0379572116637947

34. Jones AD, Cruz Agudo Y, Galway L, Bentley J, Pinstrup-Andersen P. Heavy agricultural workloads and low crop diversity are strong barriers to improving child feeding practices in the Bolivian Andes. Soc Sci Med. 2012; 75:1673-84. https://doi.org/10.1016/j.socscimed.2012.06.025.

\section{Publisher's Note}

Springer Nature remains neutral with regard to jurisdictional claims in published maps and institutional affiliations.
Ready to submit your research? Choose BMC and benefit from:

- fast, convenient online submission

- thorough peer review by experienced researchers in your field

- rapid publication on acceptance

- support for research data, including large and complex data types

- gold Open Access which fosters wider collaboration and increased citations

- maximum visibility for your research: over $100 \mathrm{M}$ website views per year

At BMC, research is always in progress.

Learn more biomedcentral.com/submissions 